\title{
High transmittance, low emissivity glass covers for flat plate collectors: Applications and performance
}

\author{
Federico Giovannetti*, Sebastian Föste, Nicole Ehrmann, Gunter Rockendorf \\ Institut für Solarenergieforschung Hameln (ISFH), Am Ohrberg 1, 31860 Emmerthal, Germany
}

\begin{abstract}
Low emissivity coatings can significantly reduce radiative heat losses of glass panes for solar energy use. Their effectiveness is strongly dependent on their optical properties, which need to meet the requirements for the specific application. The paper analyses the performance of newly developed, highly transmitting and spectrally selective glass coatings based on transparent conductive oxides (TCO) for the use in flat plate collectors: Uncovered, singleglazed and double-glazed designs are taken into consideration. As functional layers both tin-doped indium oxide and aluminum-doped zinc oxide have been investigated. Collector efficiencies and annual collector yields are presented and compared to those of state-of-the-art collectors. Theoretical calculations are complemented by measurements on collector prototypes. The results show that a significant performance increase is accessible both in single-glazed collectors with low or non-selective absorbers and in double-glazed collectors with highly selective absorbers.
\end{abstract}

(C) 2012 The Authors. Published by Elsevier Ltd. Open access under CC BY-NC-ND license.

Selection and/or peer-review under responsibility of PSE AG

Keywords: coated glass; low emissivity; flat plate collector.

\section{Introduction}

Spectrally selective glass has been investigated since long time both for active and passive solar energy use. In the literature particularly works from the 70 s and $80 \mathrm{~s}$ of the last century have discussed low emissivity (low-e) coatings for glass covers to improve the performance of different collector types $[1,2,3,4,5]$.

Due to the successful development of highly selective metal absorbers, able to reduce radiation heat losses more effectively than low-e glazings, the proposed approaches were neither put into practice nor

\footnotetext{
* Corresponding author. Tel.: +49-5151-999-501; fax: +49-5151-999-500.

E-mail address: giovannetti@isfh.de.
} 
followed up. The use of a low-e cover in a single-glazed collector with a selective absorber, which represents the most common design today on the market, doesn't provide for any improvement, but rather negatively affects the collector performance, because selective coatings on glass are responsible for additional optical losses.

For other collector configurations, however, low-e glass can be used advantageously. The crucial factors are the properties of the coating, which have to meet special requirements. Based on the optical characteristics of prototype coated panes, that are being developed for solar thermal applications as part of an ongoing research project at ISFH, the present article examines the potential of low-e glass for different designs of flat plate collectors: Single- and double glazed as wells as uncovered ones.

\begin{tabular}{|ll|}
\hline Nomenclature \\
AZO & aluminum-doped zinc oxide \\
AR & antireflective coating \\
ITO & tin-doped indium oxide \\
$\mathrm{G}$ & irradiance \\
$\mathrm{T}_{\mathrm{A}}$ & outdoor ambient temperature \\
$\mathrm{T}_{\text {Sky }}$ & sky temperature \\
$\alpha_{\mathrm{e}}$ & solar absorptance \\
$\varepsilon$ & emissivity \\
$\tau_{\mathrm{e}}$ & solar transmittance \\
\hline
\end{tabular}

\section{Requirements for spectrally selective glass}

Glass represents an ideal material for the use in solar energy applications thanks to its high solar transmittance, long-term stability and low cost. To combine these advantageous properties with an additional heat protection function, spectrally selective coatings, reflecting radiation in the infrared wavelength range, can be applied to its surface, thus significantly reducing thermal losses.

Suitable active materials for the coating, due to their physical properties, are either metals (mainly silver, but also copper or gold) or metal oxides (e.g. tin oxide, indium oxide or zinc oxide). These are embedded in appropriate layer systems, which can be deposited with different methods on glass. The choice of the materials, the coating structure and the coating technology is crucial for defining the optical properties and the stability of the glass and thus for its application. Commercially available products have been almost exclusively developed for architecture. To ensure thermal and visual comfort in buildings, coating systems based on silver are primarily used, which can provide for extremely low emissivity (less than 0.03) and high visible transmittance (up to 0.90). Solar transmittance however is rarely higher than 0.60 . Values up to 0.75 and corresponding higher emissivity can be achieved using very thin silver layers, which have been developed in the last years for triple glazing, or with metal oxides. The results of the cited works as well as our ongoing activities at ISFH confirm that these values are not high enough for collector applications. As the efficiency of a collector results from solar gains and thermal losses, proper combinations of the optical properties of a low-e cover (solar transmittance and emissivity) can theoretically be calculated, which lead to a higher performance than a conventional non-coated glass pane 
for different operating temperatures and collector constructions.

Beside the performance of the coating, its resistance to temperature, humidity, mechanical stress and their combined effect, depending on the configuration and corresponding exposure, plays a significant role in solar thermal collectors. Silver coatings for architectural glass, for example, are very sensitive to corrosion and can only be used in a dry and airtight environment, such as in the gap of multiple insulating glazing.

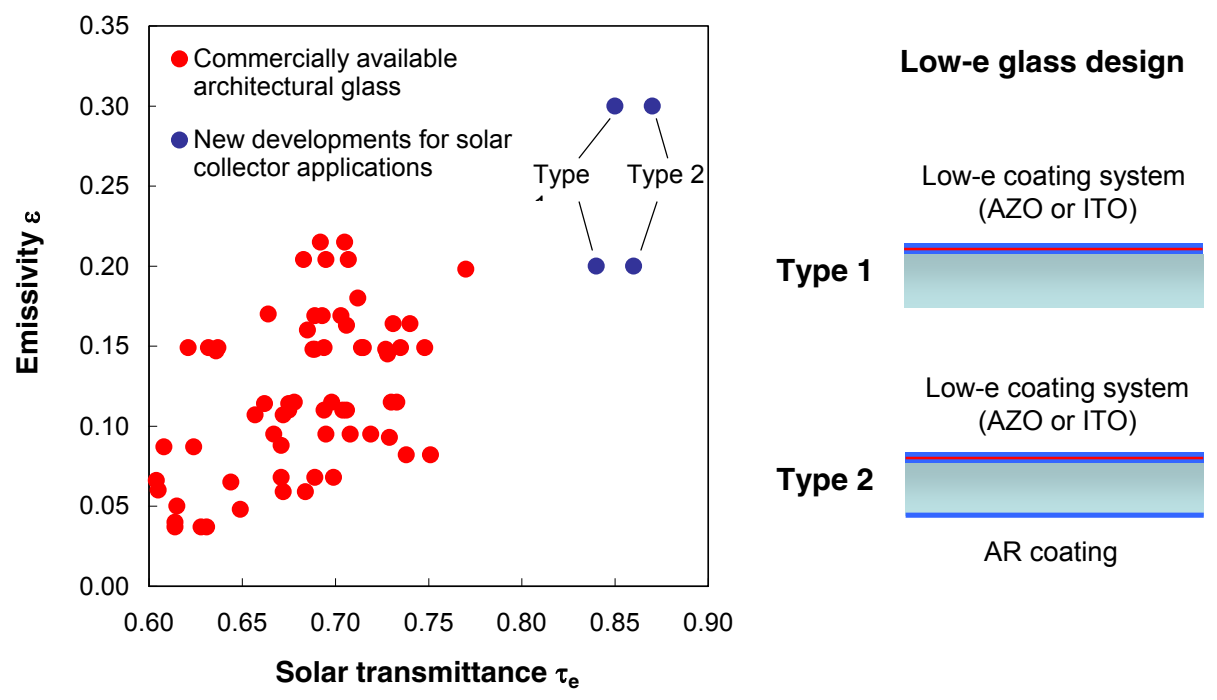

Fig. 1. Left: Optical properties of spectrally selective glass with high solar transmittance for architecture [6] and solar collector applications (results from own measurements and simulations) in comparison. Right: Schematic composition of the newly developed glass

As last criterion, the cost effectiveness of the coating (materials and coating technologies) has to be taken into account to ensure that the benefits (increased collector yield) can justify the additional expenses.

On the basis of these requirements, we are currently investigating and optimizing within an ongoing project in cooperation with industry partners two layer systems based on transparent conductive oxides: aluminum-doped zinc oxide (AZO) and tin-doped indium oxide (ITO). The two systems differ in terms of performance, stability and cost: The ITO coating exhibits a higher chemical resistance as well as a lower emissivity at a comparable solar transmittance, thus providing for a better thermal insulation. Due to the limited availability of this material, the AZO coating, however, has to be favored with regard to ecology and economics.

Our investigations on the AZO system have shown promising results in laboratory [7]; currently we are working at scaling the coating to large sizes while maintaining the achieved performance and durability. The ITO-coated pane is a special architectural glass, manufactured by the German company Euroglas, which is being adapted and optimized for the use in thermal collectors. The coating is originally intended for the use on the outer side of highly insulated multiple glazing to avoid condensation and it is therefore particularly resistant against weathering and mechanical loads (class A according to EN 1096-2 [8]). Long-term temperature stress tests up to $140{ }^{\circ} \mathrm{C}$ at ISFH confirm its very good durability. First measurements on collector prototypes have been successfully completed as well, as shown in the following section. 
Optical measurements at ISFH on prototype glass panes with different coating composition (material, thickness of the active layer, doping etc.) report a solar transmittance between 0.83 and 0.86 as well as a normal emissivity between 0.19 and 0.30 . To further increase the performance of the glass in the solar spectral range, an additional antireflective coating can be applied on the uncoated side of the pane. A gain of about 0.02 is expected (s. Figure 1).

Our current R\&D activities aim primarily at the development of highly efficiency double-glazed collectors $[9,10]$. The approach and the results with regards to the coating, however, are to a large extent transferable to other collector configurations and they are used for the present study.

\section{Application in flat plate collectors}

Based on the optical characteristics of the newly developed low-e glass its potential for the use in solar thermal flat plate collectors is investigated by means of calculation of the efficiency and the annual yield. The theoretical calculations are supported by experimental results for exemplary constructions. The basic data of the glass used for the comparative study are listed in Table 1.

Table 1. Optical properties of the glass types used for the theoretical calculations

\begin{tabular}{llcc}
\hline Glass design & Name & Solar transmittance $\tau_{\mathrm{e}}$ & Emissivity $\varepsilon$ \\
\hline Low iron glass & $\mathrm{REF}$ & 0.90 & 0.84 \\
Low iron antireflective glass & $\mathrm{AR}$ & 0.96 & 0.84 \\
$\mathrm{AZO} /$ low iron glass & $\mathrm{AZO}_{\min }$ & 0.85 & 0.30 \\
$\mathrm{AZO} /$ low iron glass / AR & $\mathrm{AZO}_{\max }$ & 0.87 & 0.30 \\
$\mathrm{ITO} /$ low iron glass & $\mathrm{ITO}_{\min }$ & 0.84 & 0.20 \\
ITO / low iron glass / AR & $\mathrm{ITO}_{\max }$ & 0.86 & 0.20 \\
\hline
\end{tabular}

The selected values of solar transmittance and emissivity for the coated panes correspond to the optimum range, which is accessible by variation of the coating structure and the manufacturing parameters, according to the current state of development.

\subsection{Uncovered collectors}

Uncovered collectors are the simplest construction for the active utilization of solar energy and can be advantageously implemented in systems and processes operating slightly above ambient temperature. The most common application is the heating of water for outdoor swimming pools, for which inexpensive plastic products are mainly in use.

Another promising field of application is the renewable support of heat supply systems for hot water production, space heating or cooling, which has been taken anew into consideration within the last years due to growing market of heat pumps. In this case high-quality metallic absorbers are requested, which can replace parts of the building envelope (roofs or façades) and take over the corresponding functions, both in new buildings and building renovation $[11,12]$.

As alternative to the state-of-the-art we propose a new collector design combining a low-e glass to a heat exchanger. This collector can operate at higher temperatures compared to common products due to its spectrally selectivity, even if the additional optical losses of the glass must be taken into account. With the exception of the stainless steel collector of the Swiss company Energie Solaire, exclusively nonselective uncovered collectors are presently on the market. Previous experience with partially selective 
metallic absorbers shows that in most cases aging effects (i.e. oxidation) lead to a significant increase in the emissivity and to a corresponding impairment of the original functionality [13]. Research activities report on very promising results with selective weather-resistant paints: depending on the color used, emissivity values between 0.3 and 0.4 have been achieved [14]. To our knowledge no commercial product is currently available.

The advantage of the presented construction compared to common selective absorbers is the spatial separation of the two functions solar absorption (under the outer glass surface) and low thermal emissivity (on the glass surface), so that regardless of the absorbing layer used a constant low emissivity is ensured.

This construction allows great design flexibility, as substrates with arbitrary colors and patterns can be combined with the coated pane. Thus, both the energetic and the architectural requirements for the building envelope can be fulfilled. To evaluate the concept feasibility we have carried out first investigations on a prototype collector. The test-collector consists of a tube-plate copper absorber coated with an inexpensive non-selective black paint $\left(\alpha_{\mathrm{e}}=0.95, \varepsilon=0.85\right)$ and a commercial low-e glass (KGlass ${ }^{\mathrm{TM}}$ from Pilkington), which are mechanically fixed to each other. To ensure the stability of the structure the composite absorber is built into a wooden frame with a rear base plate. The collector performance has been measured at different wind speeds according to EN 12975-2, the corresponding efficiency curves are shown in Figure 2.

low-e glass

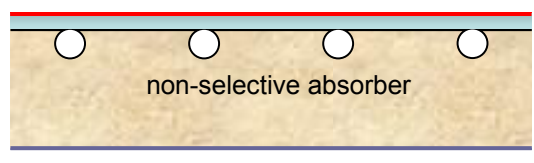

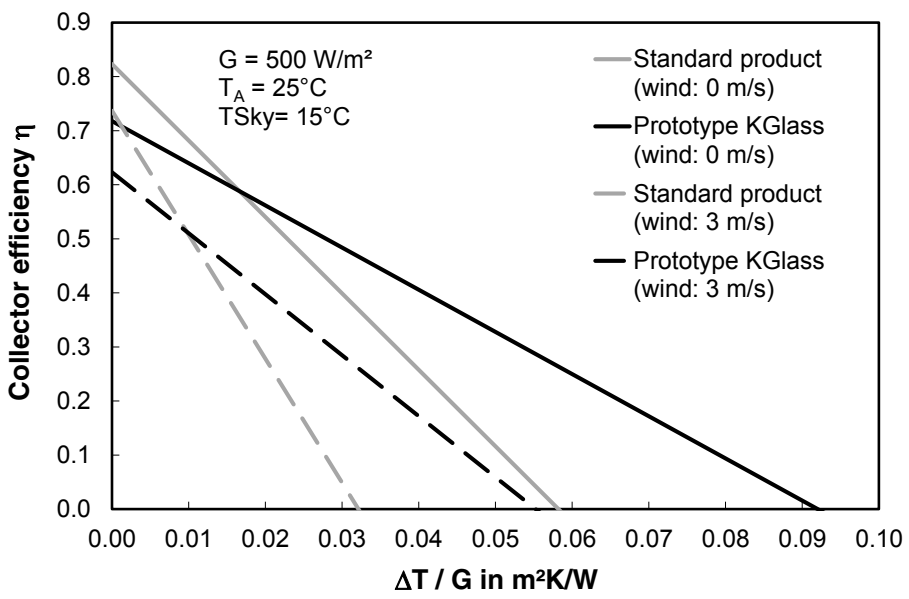

Fig. 2. Left: Schematic design of the investigated uncovered collector. Right: Measured efficiency curves of a prototype uncovered collector at different wind speeds. The collector consists of a tube-plate copper absorber and a low-e glass pane (KGlass ${ }^{\mathrm{TM}}$ from Pilkington: $\tau_{\mathrm{e}}=0.71, \varepsilon=0.18$ ), which are mechanically fixed to each other. For comparison the efficiency curve of a typical nonselective uncovered collector is also depicted in the graph. To enable the comparison of selective and non-selective collectors the curves refer to the solar irradiance $\mathrm{G}$ and not to the net irradiance

The results confirm the expected performance increase at higher inlet temperatures or/and lower irradiance levels compared to conventional non-selective uncovered products. The low optical efficiency depends both on the solar transmittance of the glass pane used $\left(\tau_{\mathrm{e}}=0.71\right)$ and on the suboptimal connection between the glass and the heat exchanger in our prototype, responsible for additional reflection losses and a lower collector efficiency factor F'. The graph attests the characteristic sensitivity of uncovered collectors to weather influence: At high wind speeds and with corresponding high convection heat losses the positive effect of the selective coating plays a minor role. 

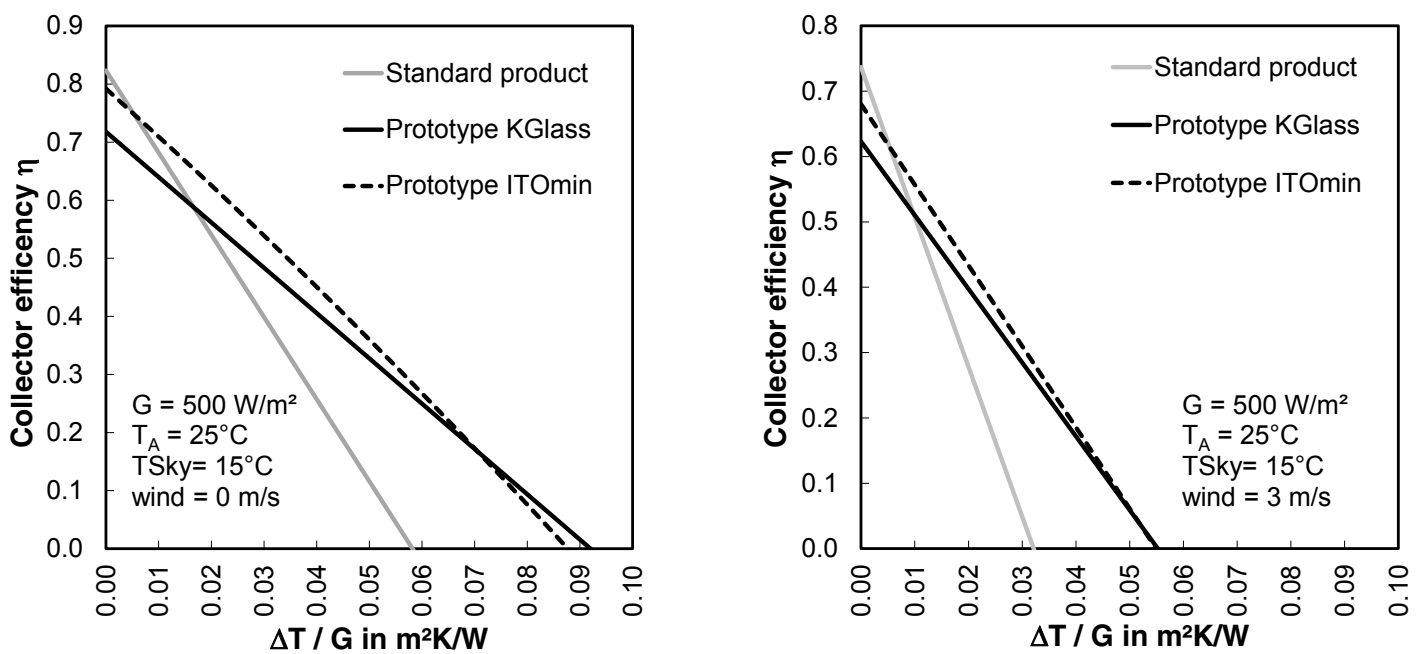

Fig. 3. Calculated efficiency curves of the optimized uncovered collector at different wind speeds. The commercial glass KGlass ${ }^{\mathrm{TM}}$ is replaced by the prototype glass ITO $_{\min }$. The pane is supposed to be bonded face-to-face and thus properly thermally coupled to the heat exchanger, which in this case serves as absorber as well. For comparison the efficiency curves of a typical uncovered product and of the measured prototype collector are depicted in the graph

To evaluate the optimization potential of the collector, we carry out simulations on a modified design, by substituting the commercial glass with our newly developed low-e panes and assuming a suitable fixing of the glass, in order to reduce the optical losses at the inner boundary surface. For the calculation we use the optical data of the glass $\mathrm{ITO}_{\min }$ (s. Table 1). The coating system based on aluminum-doped zinc oxide cannot provide for the necessary stability so far and hasn't been taken into consideration for this application. The results are depicted in Figure 3 and attest an increase of about 7 points in the conversion factor (from 0.72 to 0.79 , with no wind), thus enabling the collector to compete with conventional uncovered products even at low operating temperatures. Starting from $\Delta \mathrm{T} / \mathrm{G}$ values of 0.006-0.01, which correspond to a difference of only $3-5 \mathrm{~K}$ above ambient air temperature at $500 \mathrm{~W} / \mathrm{m}^{2}$, the low-e collector is better performing than the reference one. The slightly higher loss coefficient in comparison to the measured prototype can be explained by the assumed good thermal coupling between the glass pane and the heat exchanger.

Open questions concerning the collector construction, its performance and reliability under natural conditions are currently being investigated at ISFH. Our work focuses especially on the influence of the real wind speed and condensate on the efficiency and functionality of the low-e coating.

\subsection{Single-glazed collectors}

In conventional single-glazed collectors with highly selective absorbers the glass cover is requested to provide for a very high solar transmittance. Glass substrates with low iron content and broadband antireflective coatings are implemented to achieve this goal. The use of a low-e coating does impair the collector performance, as spectral selectivity cannot be achieved without reducing the solar transmittance of the cover. Moreover, no further significant reduction of heat losses can be expected, because convection is the dominant heat transfer mechanism in the air-gap between the selective absorber and the cover. Evacuated flat plate collectors, which are currently under development within different R\&D activities, represent an exception in this category: Due to the total suppression of convection losses, a 
low-e cover may improve the collector performance at high temperatures. Quantitative data are difficult to produce, because they are strongly dependent on the specific collector design and on the corresponding conductive heat losses. This special design is on that account not considered in the present work.

The situation is different if the glass cover is combined with non-selective or low-selective absorbers (s. Figure 4). Low-e coatings can in this case positively affect the collector performance. The influence depends both on the operating temperature and on the optical properties of the absorber (solar absorptance $\alpha_{\mathrm{e}}$ and thermal emissivity $\varepsilon$ ).
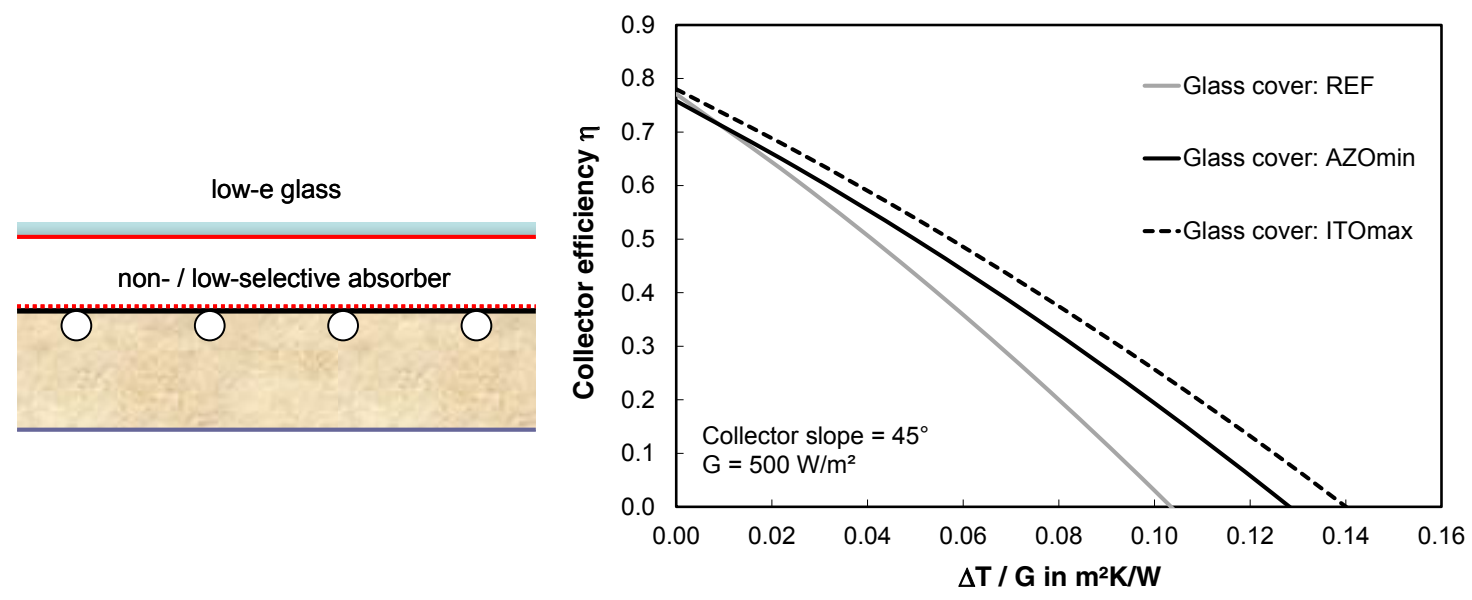

Fig. 4. Left: Investigated collector design. Right: Calculated efficiency of a single-glazed flat collector with a non-selective absorber $(\alpha=0.95, \varepsilon=0.85)$ and different glass covers $\left(\mathrm{REF}, \mathrm{AZO}_{\min }\right.$ and $\mathrm{ITO}_{\max }$ refer to the values reported in Table 1). The collector features $50 \mathrm{~mm}$ back insulation

Possible applications are roof or façade cladding, intended as components of domestic or industrial, solar assisted heat supply systems, as already mentioned in the previous section. Compared to uncovered collectors, the use of a glass cover and the resulting air gap between glass and absorber can significantly reduce the heat losses, thus extending the operating temperature range of the system.

In the present work we investigate the influence of two low-e different glazing $\left(\mathrm{AZO}_{\min }\right.$ and $\left.\mathrm{ITO}_{\max }\right)$ by means of simulations of the annual gross collector yield at different constant inlet temperatures.

The absorber emissivity is varied between 0.05 and 0.85 , the absorptance between 0.65 and 0.95 , in order to take also colored collectors into consideration, which represent an attractive architectural option for building integration. The calculations are carried out with the simulation tool TRNSYS and refer to a southward oriented plane with a slope of $45^{\circ}$, using the Meteonorm weather data of Zürich (Switzerland). For comparison a common low iron (REF) and an antireflective (AR) glass cover are used.

The results at an inlet temperature of $40{ }^{\circ} \mathrm{C}$ are reported in Figures 5 and 6 . The substitution of a low iron pane is disadvantageous up to an absorber emissivity of approximately $0.25\left(\mathrm{AZO}_{\min }\right)$ and 0.15 $\left(\mathrm{ITO}_{\max }\right)$. With a non-selective absorber, on the other hand, a performance increase up to $20-25 \%$ $\left(\mathrm{AZO}_{\min }\right)$ and $30-35 \%\left(\mathrm{ITO}_{\max }\right)$ respectively can be achieved. Compared to an antireflective cover, the use of the low-e glass impairs the collector performance up to an emissivity of about $0.55\left(\mathrm{AZO}_{\min }\right)$ and 0.45 $\left(\mathrm{ITO}_{\mathrm{min}}\right)$. Despite the significantly lower solar transmittance of the spectrally selective panes, an improvement between $10 \%$ and $20 \%$ is still expected in case of colored, non-selective absorbers. At higher operation temperatures the benefit of the low-e coating is obviously even more pronounced. 

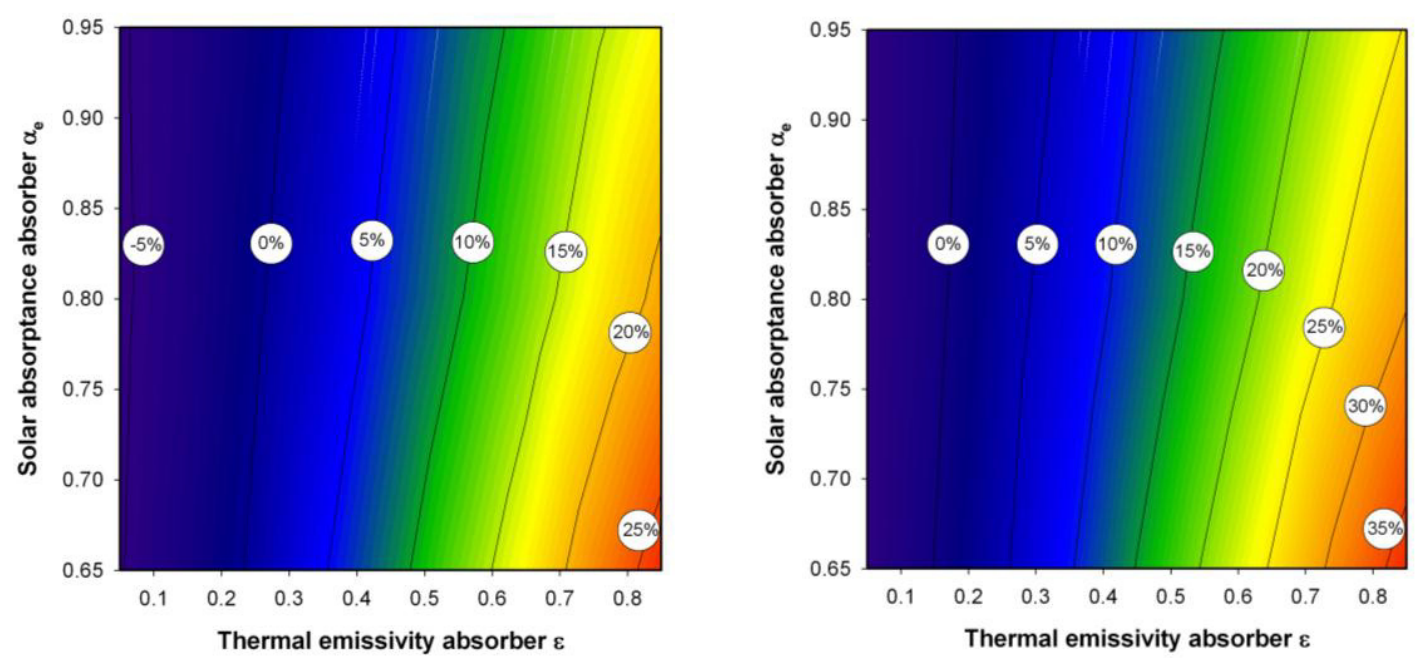

Fig. 5. Increment in annual gross yield of a single-glazed flat plate collector at an inlet temperature of $40{ }^{\circ} \mathrm{C}$ by substituting the common low iron glass cover (REF) with low-e coated glass (left: $\mathrm{AZO}_{\min }$; right: $\mathrm{ITO}_{\max }$ ) in dependence of the optical properties of the absorber plate. Simulation parameters: south orientation, $45^{\circ}$ collector slope, weather data of Zürich (Switzerland)
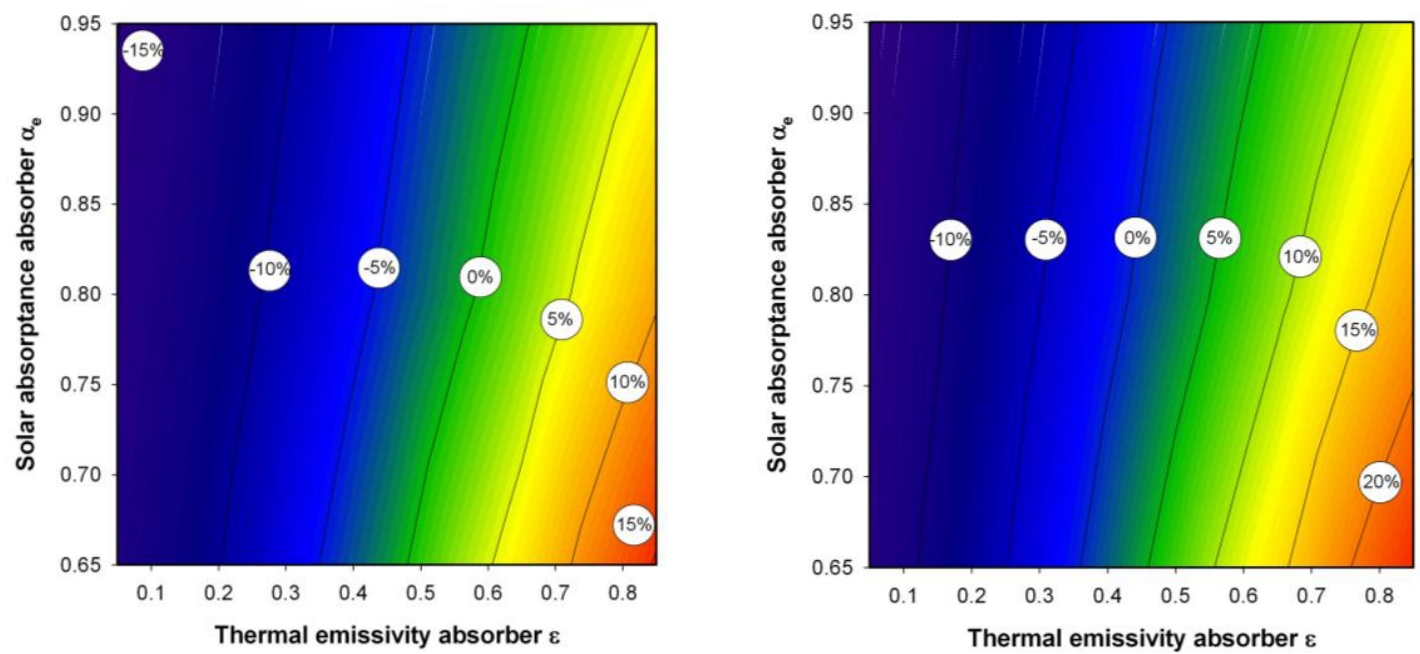

Fig. 6. Increment in annual gross yield of a single-glazed flat plate collector at an inlet temperature of $40{ }^{\circ} \mathrm{C}$ by substituting the antireflective, low iron glass cover (AR) with low-e coated glass (left: $\mathrm{AZO}_{\min }$; right: $\mathrm{ITO}_{\max }$ ) in dependence of the optical properties of the absorber plate. Simulation parameters: south orientation, $45^{\circ}$ collector slope, weather data of Zürich (Switzerland)

\subsection{Double-glazed collectors}

Double-glazed covers for high efficiency flat plate collectors (s. Figure 7, left) offer another promising application of spectrally selective glass. The solar absorber in this case is assumed to be highly selective $(\varepsilon=0.05)$. The low-emitting coating can inhibit the radiative heat transfer between the two glass panes, thus effectively reducing the thermal losses through the collector aperture. 

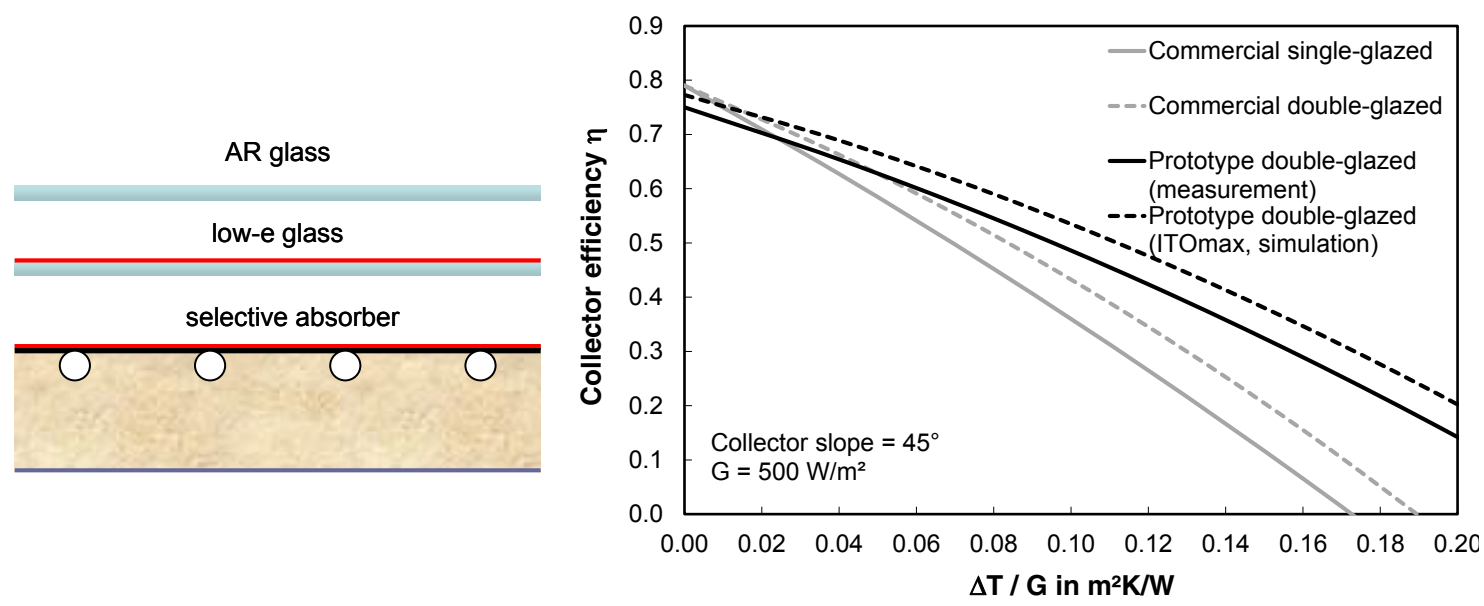

Fig. 7. Left: Design of the investigated double-glazed collector with low-e glass. Right: Efficiency curves of double-glazed collectors with two different types of low-e glass compared to those of commercial single- and double-glazed collectors with nonselective cover. The double-glazed collectors feature a $70 \mathrm{~mm}$ back insulation, the single-glazed a $50 \mathrm{~mm}$ one

The coating is applied on the outer side of the inner glass, in order to reduce the optical losses and to advantageously profit of the absorbed radiation subsequently released inward.

This approach has been already theoretically investigated in previous works [1,2], current activities at ISFH in cooperation with industry partners are focusing on the actual implementation of the concept into practice. The low-e glass is combined with a sealed, argon-filled gap, with the aim to increase the collector performance at higher operating temperatures or/and lower irradiance levels. Predestined applications include the production of process heat, solar space heating with high solar fraction and solar cooling. In comparison to evacuated tube collectors, benefits concerning cost, reliability and building integration are expected.

Experimental results with first prototypes confirm the theoretical calculations: At a temperature difference of $60 \mathrm{~K}$ between collector fluid and ambient air and at an irradiance of $500 \mathrm{~W} / \mathrm{m}^{2}(\Delta \mathrm{T} / \mathrm{G}=0.12$ $\left.\mathrm{m}^{2} \mathrm{~K} / \mathrm{W}\right)$, the prototype exhibits an efficiency, which is $60 \%$ higher than that of a common single-glazed flat plate collector (s. Figure 6, right). By comparison with a commercially available double-glazed flat plate collector with two non-selective AR-glass panes, the increase amounts to $23 \%$, mainly due to the selective coating. The use of low-e glass with higher transmission and lower emissivity can provide for a further improvement: According to our simulations for the glass $\mathrm{ITO}_{\max }$ a performance enhancement of $80 \%$ and $38 \%$ respectively, compared to the mentioned commercial products, is expected. For detailed information regarding the collector concept and the current state of development it is referred to the contributions already cited $[9,10]$.

\section{Conclusion}

New glass coatings with high solar transmittance and low emissivity based on transparent conductive oxides (TCO) enable innovative collector designs. This article presents and discusses the results of our investigations on uncovered, single and double-glazed flat plate collectors.

In single-glazed collectors with highly selective absorbers, which represent the state-of-the-art and are the most common collector type in the European market, a spectrally selective cover doesn't lead to any improvement, but rather impairs the collector efficiency due to the additional optical losses of the coating. 
For different collector assemblies on the other hand, low-e coated glass can result in a significant performance improvement. On the basis of the optical data of newly developed coated glass, we analyze its potential in comparison to conventional covers. The results show that a significant increase in efficiency is accessible both in single-glazed collectors with low or non-selective absorbers and in double-glazed collectors with highly selective absorbers.

Furthermore, we present a novel concept of uncovered collector, featuring great design flexibility and thus representing an attractive architectural solution for building integration. Preliminary experimental investigations confirm the expectations.

\section{Acknowledgements}

Part of the work presented in this publication was funded by the German Ministry for the Environment, Nature Conservation and Nuclear Safety, based on a decision of the German Parliament (contract number: 0325973). The authors are grateful for this support and thank the project partners, especially the flat glass manufacturer Euroglas $\mathrm{GmbH}$, for the fruitful cooperation. The content of this publication is in the responsibility of the authors.

\section{References}

[1] Goodman R. D., Menke A. G., 1975. Effect of cover plate treatment on efficiency of solar collectors, Solar Energy 17, $207-$ 211

[2] Apfel J. H., 1975. Optical coatings for collection and conservation of solar energy. J. Vac. Sci. Technol, 12 (5), 1016-1022

[3] Fan J. C. C., Bachner F. J., 1976. Transparent heat mirrors for solar-energy applications, Applied Optics 15 (4), $1012-1017$

[4] Yoshida S., 1978. Efficiency of Drude mirror-type selective transparent filters for solar thermal conversion, Applied Optics, 17 (1), $145-150$

[5] Frank G., Kauer E., Köstlin H., Schmitte F. J., 1983. Transparent heat-reflecting coating for solar applications based on highly doped tin oxide und indium oxide, Solar Energy Materials 8, 387-398

[6] LBNL - Lawrence Berkeley National Laboratory, 2012. International Glazing Database - Version 18, http://windows.lbl.gov/materials/IGDB/

[7] Ehrmann N., Reineke-Koch R., 2012. Selectively coated high efficiency glazing for solar-thermal flat-plate collectors, Thin Solid Films 520, 4214-4218

[8] EN 1096-2: 2012. Glass in building - Coated glass - Part 2: Requirements and test methods for class A, B and S coatings

[9] Föste S. et al., 2012. Thermal Insulation for High Efficiency Flat Plate Collectors, Proceedings EuroSun 2012, Rijeka, Croatia, to be published

[10] Föste S. et al., 2011. Basics for the development of a high efficiency flat-plate collector with a selectively coated double glazing, Proceedings ISES Solar World Congress 2011, Kassel, Germany, 82-87

[11] Bertram E., Glembin J., Scheuren J., Rockendorf G., 2009. Soil regeneration by unglazed solar collectors in heat pump systems, Proceedings ISES Solar World Congress 2009, Johannesburg, South Africa

[12] Burch J., Salasovich J., 2005. An Assessment of Unglazed Solar Domestic Water Heaters, Proceedings ISES Solar World Congress, Orlando, Florida, 6-12 August 2005

[13] ISFH, 2012. Personal communication of the test center of the Institut für Solarenergieforschung Hameln

[14] Orel B., Spreizer H., Fir M., Surca Vuk A., Merlini D., Vodlan M., Kohl M., 2007. Selective paint coatings for coloured solar absorbers: polyurethane thickness insensitive spectrally selective (TISS) paints (Part II), Solar Energy Material and Solar Cells $30,77-94$ 